\title{
MtDNA mutations linked with left ventricular hypertrophy
}

\author{
Margarita A. Sazonova ${ }^{1,2}$, Vasily V. Sinyov ${ }^{1}$, Anastasia I. Ryzhkova², Marina D. Sazonova ${ }^{2}$, \\ Zukhra B. Khasanova1, Igor A. Sobenin ${ }^{1,2}$ \\ 'Laboratory of Medical Genetics, National Medical Research Center of Cardiology, Moscow 121552, The Russian Federation. \\ ${ }^{2}$ Laboratory of Angiopathology, Institute of General Pathology and Pathophysiology, Moscow 125315, The Russian Federation.
}

Correspondence to: Dr. Margarita A. Sazonova, Laboratory of Medical Genetics, National Medical Research Center of Cardiology, 15a 3rd Cherepkovskaya Str, Moscow 121552, The Russian Federation. E-mail: margaritaasazonova@gmail.com

How to cite this article: Sazonova MA, Sinyov VV, Ryzhkova Al, Sazonova MD, Khasanova ZB, Sobenin IA. MtDNA mutations linked with left ventricular hypertrophy. Vesse/ Plus 2019;3:5. http://dx.doi.org/10.20517/2574-1209.2018.56

Received: 24 July 2018 First Decision: 27 Nov 2018 Revised: 11 Jan 2019 Accepted: 16 Jan 2019 Published: 26 Feb 2019

Science Editor: Igor A. Sobenin Copy Editor: Cai-Hong Wang Production Editor: Huan-Liang Wu

\begin{abstract}
Aim: In left ventricular hypertrophy (LVH), the heart muscle thickens. One third of individuals with LVH never complain of heart problems. However, such patients have a high risk of sudden death. LVH can be caused by arterial atherosclerotic lesions. The linkage of mtDNA mutations 652insG, m.5178C >A, m.3336T>C, m.14459G >A, 652delG, m.14846G>A, m.1555A>G, m.15059G >A, m.3256C>T, m.12315G >A and m.13513G>A with atherosclerosis was described earlier by our laboratory. The aim of the study was to analyze the linkage of these mtDNA mutations with LVH.
\end{abstract}

Methods: DNA from white blood cells was isolated using a phenol-chloroform method. PCR-fragments of DNA contained the region of the investigated mutations. The heteroplasmy level of mtDNA mutations was analyzed using a pyrosequencing-based method developed by our laboratory.

Results: We investigated two groups of individuals. One hundred and ninety-four patients with LVH. Two hundred and ten were conventionally healthy. It was found that mtDNA mutation m.5178C $>$ A was significantly associated with LVH. Single nucleotide replacement m.1555A $>\mathrm{G}$ was associated with $\mathrm{LVH}$ at the level of significance $P \leq 0.1$. At the same time m.12315G >A and m.3336T>C were significantly associated with the absence of this pathology. Single nucleotide replacement m.14459G $>$ A was associated with the absence of $\mathrm{LVH}$ at the significance level $P \leq 0.1$.

Conclusion: MtDNA mutations m.5178C >A and m.1555A>G can be used for molecular genetic assessment of the predisposition of individuals to the occurrence of left ventricular hypertrophy. They can also be used for the family analysis of this pathology. Mutations m.12315G >A, m.3336T>C and m.14459G>A can be used in the development of LVH gene therapy methods.

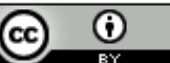

(C) The Author(s) 2019. Open Access This article is licensed under a Creative Commons Attribution 4.0 International License (https://creativecommons.org/licenses/by/4.0/), which permits unrestricted use, sharing, adaptation, distribution and reproduction in any medium or format, for any purpose, even commercially, as long as you give appropriate credit to the original author(s) and the source, provide a link to the Creative Commons license, and indicate if changes were made. 
Keywords: Left ventricular hypertrophy, heteroplasmy level, mutation, mitochondrial genome, mtDNA

\section{INTRODUCTION}

In case of left ventricular hypertrophy (LVH), the heart muscle thickens. Often septum between the left and right ventricles mutates in this disease ${ }^{[1]}$. In LVH muscle fibers in the myocardium are arranged randomly. The main criterion for $\mathrm{LVH}$ is considered to be an increase in myocardial thickness larger than or equal to $1.5 \mathrm{~cm}$ in the presence of left ventricular diastolic dysfunction ${ }^{[1-3]}$. The third part of individuals with LVH never complain of heart problems. However, such patients have a high risk of sudden death, which reaches $4 \%$ per year ${ }^{[2,3]}$. Echocardiography helps to identify such patients. It can be used to identify a left ventricle and left atrium enlargements. It can also detect heart rhythm disorders. This helps to assess the risk of sudden death. About $50 \%$ of deaths from left ventricular hypertrophy per year happen precisely because of ventricular arrhythmias. The second cause of death of patients with LVH is congestive heart failure. It is most common in patients older than 40 years ${ }^{[4,5]}$.

The onset and development of left ventricular hypertrophy can be caused by atherosclerotic lesions of the arteries, in particular, atherosclerotic plaques and thickening of the intima-medial layer of these vessel ${ }^{[6-10]}$. Risk factors for LVH include diabetes mellitus, stress, smoking, hyperlipoproteinemia, hypodynamia, arterial hypertension, hyperfibrinogenemia, homocysteinemia, obesity, hypothyroidism and metabolic syndrome $e^{[11-15]}$.

In addition, left ventricular hypertrophy may occur due to hereditary and somatic mutations of the human genome. At present, many scientists are studying, basically, the single-nucleotide polymorphism (SNP) of the nuclear genome associated with this pathology ${ }^{[16-20]}$. However, nuclear polymorphisms are associated only with a small number of LVH cases. Meanwhile mitochondrial genome mutations with left ventricular hypertrophy were analyzed by a very small number of research groups around the world $\mathrm{d}^{[21-23]}$.

It should be noted that in human cells there are plenty of mitochondria. Each mitochondria contains several copies of the mitochondrial genome. Therefore, during the analysis of DNA samples from the study participants it is necessary to determine the heteroplasmy level of each investigated mitochondrial genome mutation (ratio of mtDNA molecules containing the mutation to the total number of mtDNA molecules) ${ }^{[24-28]}$. It differs significantly from SNP analysis of the nuclear genome, where it is necessary to identify homozygous and heterozygous individuals according to this SNP.

The linkage of mtDNA mutations 652insG, m.5178C >A, m.3336T>C, m.14459G $>$ A, 652delG, m.14846G $>$ A, m.1555A > G, m.15059G $>A, m .3256 \mathrm{C}>\mathrm{T}, \mathrm{m} .12315 \mathrm{G}>\mathrm{A}$ and $\mathrm{m} .13513 \mathrm{G}>\mathrm{A}$ with atherosclerosis was described earlier by our laboratory researchers ${ }^{[24,28-31]}$. Since LVH has common risk factors with atherosclerosis, it was decided to analyze the relationship of these mutations to mtDNA with left ventricular hypertrophy.

\section{METHODS}

In this study two groups of study participants were examined. One hundred and ninety-four patients had left ventricular hypertrophy. Two hundred and ten study participants were conventionally healthy. For identifying patients with LVH among the study participants, the method of echocardiography was used. The main criterion of LVH was considered to be an increase in myocardial thickness of more than or equal to $1.5 \mathrm{~cm}$ in the presence of left ventricular diastolic dysfunction. Individuals with diabetes mellitus, hypercholesterolemia and patients, who used drugs, were excluded from the study. In order to compare the samples of patients with LVH and conventionally healthy study participants more correctly, the composition of the samples was changed so that they did not contain significant differences in age, sex, diastolic and systolic blood pressure. 
Clinical, anthropometric and age characteristics were determined for patients with left ventricular hypertrophy and conventionally healthy individuals [Tables 1 and 2]

The study was carried out in accordance with the Declaration of Helsinki. The study protocol was inspected and approved by the Ethics Committee of the National Medical Research Center of Cardiology. Each study participant has signed a written informed consent to participate in this investigation.

DNA from white blood cells was isolated using the phenol-chloroform method ${ }^{[32-34]}$. PCR-fragments of DNA were obtained. They contained the region of studied mutations (652insG, m.5178C >A, m.3336T>C, m.14459G $>$ A, 652delG, m.14846G $>$ A, m.1555A $>$ G, m.15059G $>$ A, m.3256C $>$ T, m.12315G $>$ A and m.13513G $>A$ ). It should be noted that biotin was attached to one of the DNA chains of the PCR fragment using the primer "bio-" (biotinylated). This was necessary for the analysis of the biotinylated DNA chain of the investigated amplificate using the pyrosequencing ${ }^{[35-37]}$.

PCR primer sequences, taken for the present reseach ${ }^{[24,26,28-30]}$ :

1. For m.652insG

F: TAGACGGGCTCACATCAC (621-638)

R: bio-GGGGTATCTAATCCCAGTTTGGGT (1087-1064)

2. For $\mathrm{m} .5178 \mathrm{C}>\mathrm{A}$

F: bio-GCAGTTGAGGTGGATTAAAC (4963-4982)

R: GGAGTAGATTAGGCGTAGGTAG (5366-5345)

3. For $\mathrm{m} .3336 \mathrm{~T}>\mathrm{C}$

F: bio-AGGACAAGAGAAATAAGGCC (3129-3149)

R: ACGTTGGGGCCTTTGCGTAG (3422-3403)

4. For $\mathrm{m} .14459 \mathrm{G}>\mathrm{A}$

F: CAGCTTCCTACACTATTAAAGT (14303-14334)

R: bio-GTTTTTTTAATTTATTTAGGGGG (14511-14489)

5. For m.652delG

F: TAGACGGGCTCACATCAC (621-638)

R: bio-GGGGTATCTAATCCCAGTTTGGGT (1087-1064)

6. For $\mathrm{m} .14846 \mathrm{G}>\mathrm{A}$

F: bio-CATTATTCTCGCACGGACT (14671-14689)

R: GCTATAGTTGCAAGCAGGAG (15120-15100)

7. For $m .1555 A>G$

F: TAGGTCAAGGTGTAGCCCATGAGGTGGCAA (1326-1355)

R: bio-GTAAGGTGGAGTGGGTTTGGG (1704-1684)

8. For $\mathrm{m} .15059 \mathrm{G}>\mathrm{A}$

F: bio-CATTATTCTCGCACGGACT (14671-14689)

R: GCTATAGTTGCAAGCAGGAG (15120-15100)

9. For $\mathrm{m} .3256 \mathrm{C}>\mathrm{T}$

F: bio-AGGACAAGAGAAATAAGGCC (3129-3149)

R: ACGTTGGGGCCTTTGCGTAG (3422-3403)

10. For $\mathrm{m} .12315 \mathrm{G}>\mathrm{A}$

F: bio-CTCATGCCCCCATGTCTAA (12230-12249)

R: TTACTTTTATTTGGAGTTGCAC (12337-12317)

11. For $\mathrm{m} .13513 \mathrm{G}>\mathrm{A}$

F: CCTCACAGGTTTCTACTCCAAA (13491-13512)

R: bio-AAGTCCTAGGAAAGTGACAGCGAGG (13825-13806) 
Table 1. Clinical and anthropometric characteristics of the groups of individuals

\begin{tabular}{|c|c|c|c|}
\hline Characteristic & $\begin{array}{c}\text { Patients with left ventricular } \\
\text { hypertrophy/standard deviation }\end{array}$ & $\begin{array}{c}\text { Conventionally healthy individuals/ } \\
\text { standard deviation }\end{array}$ & $\begin{array}{c}\text { Significance of } \\
\text { differences }\end{array}$ \\
\hline Diastolic blood pressure, $\mathrm{mmHg}$ & $86 / 23$ & $83 / 17$ & 0.395 \\
\hline Systolic blood pressure, $\mathrm{mmHg}$ & $128 / 23$ & $122 / 21$ & 0.228 \\
\hline Age, years & $64 / 8.6$ & $58 / 8.2$ & 0.119 \\
\hline Smoking, \% & 35 & 28 & 0.111 \\
\hline Sex (man/women) & $112 / 82$ & $94 / 116$ & 0.118 \\
\hline Body mass index, $\mathrm{kg} / \mathrm{m}^{2}$ & $33.8 / 4.5$ & $28.9 / 4.1$ & 0.149 \\
\hline Total cholesterol, mol/L & $6.51 / 1.12$ & $6.45 / 1.05$ & 0.135 \\
\hline Triglycerides, $\mathrm{mol} / \mathrm{L}$ & $1.65 / 0.64$ & $1.48 / 0.61$ & 0.115 \\
\hline High-density lipoprotein, mol/L & $1.55(0.53)$ & $1.68(0.44)$ & 0.104 \\
\hline Low-density lipoprotein, mol/L & $4.36(1.23)$ & $4.04(1.21)$ & 0.142 \\
\hline
\end{tabular}

Table 2. Age of participants in the study groups

\begin{tabular}{lcccc}
\hline Groups of individuals & Age minimum & Mean age & Age maximum & Standard deviation \\
\hline Patients with left ventricular hypertrophy & 53 years old & 64 years old & 75 years old & 8.3 \\
Conventionally healthy individuals & 54 years old & 58 years old & 62 years old & 7.9 \\
\hline
\end{tabular}

PCR fragments of the following size were obtained ${ }^{[24,26,28-30]}$ :

(1) m.652insG - $467 \mathrm{bp}$;

(2) $\mathrm{m} .5178 \mathrm{C}>\mathrm{A}-383 \mathrm{bp}$;

(3) $\mathrm{m} .3336 \mathrm{~T}>\mathrm{C}-294 \mathrm{bp}$;

(4) $\mathrm{m} .14459 \mathrm{G}>\mathrm{A}-209 \mathrm{bp}$;

(5) m.652delG - $467 \mathrm{bp}$;

(6) $\mathrm{m} .14846 \mathrm{G}>\mathrm{A}-450 \mathrm{bp}$;

(7) $\mathrm{m} .1555 \mathrm{~A}>\mathrm{G}-379 \mathrm{bp}$;

(8) $\mathrm{m} .15059 \mathrm{G}>\mathrm{A}-450 \mathrm{bp}$;

(9) $\mathrm{m} .3256 \mathrm{C}>\mathrm{T}-294 \mathrm{bp}$;

(10) $\mathrm{m} .12315 \mathrm{G}>\mathrm{A}-108 \mathrm{bp}$;

(11) $\mathrm{m} .13513 \mathrm{G}>\mathrm{A}-335 \mathrm{bp}$.

The reaction mixture for PCR was $30 \mu \mathrm{L}$. It contained:

(1) $0.3 \mathrm{pM}$ of each primer;

(2) $67 \mathrm{mM}$ tris- $\mathrm{HCl}$ ( $\mathrm{pH} 8.8$ );

(3) $\mathrm{MgCl}_{2}: 2.5 \mathrm{mM}$ for m.652insG, m.5178C >A, m.3336T>C, m.652delG, m.1555A>G, m.3256C >T, m.12315G>A and m.13513G>A; $1.5 \mathrm{mM}$ for G14846A,G15059A and G14459A;

(4) $16.6 \mu \mathrm{M}\left(\mathrm{NH}_{4}\right)_{2} \mathrm{SO}_{4}$;

(5) 3 units of Taq-polymerase;

(6) $200 \mu \mathrm{M}$ of each deoxyribonucleotriphosphate;

(7) $0.4-0.6 \mu \mathrm{g}^{[24,26,28-30]}$.

Annealing temperature for the PCR is shown in Table 3.

To carry out the polymerase chain reaction, we used thermocycler "PTC DNA Engine 200".

Pyrosequencing of PCR fragments was performed on an automated pyrosequencing device PSQTMHS96MA (Biotage, Sweden).

For pyrosequencing the following primer sequences were used $\mathrm{d}^{[24,26,28-30]}$ :

1. For m.652insG 
Table 3. Annealing temperature for the $P C R^{[24,26,28-30]}$

\begin{tabular}{lc}
\hline Mutations & Annealing temperature for primers \\
\hline $\mathrm{m} .15059 \mathrm{G}>\mathrm{A}$ & \\
$\mathrm{m} .3336 \mathrm{~T}>\mathrm{C}$ & \\
$\mathrm{m} .13513 \mathrm{G}>\mathrm{A}$ & $5{ }^{\circ} \mathrm{C}$ \\
$\mathrm{m} .3256 \mathrm{C}>\mathrm{T}$ & \\
$\mathrm{m} .14846 \mathrm{G}>\mathrm{A}$ & \\
$\mathrm{m} .652 \mathrm{ins} \mathrm{C}$ & \\
$\mathrm{m} .5178 \mathrm{C}>\mathrm{A}$ & $60^{\circ} \mathrm{C}$ \\
$\mathrm{m} .652 \mathrm{delG}$ & \\
$\mathrm{m} .14459 \mathrm{G}>\mathrm{A}$ & \\
$\mathrm{m} .1555 \mathrm{~A}>\mathrm{G}$ & \\
$\mathrm{m} .12315 \mathrm{G}>\mathrm{A}$ & $50^{\circ} \mathrm{C}$ \\
\hline
\end{tabular}

CCCATAAACAAATA (639-651);

2. For $m .5178 \mathrm{C}>\mathrm{A}$

ATTAAGGGTGTTAGTCATGT (5200-5181);

3. For $\mathrm{m} .3336 \mathrm{~T}>\mathrm{C}$

TGCGATTAGAATGGGTAC (3354-3337);

4. For $\mathrm{m} .14459 \mathrm{G}>\mathrm{A}$

GATACTCCTCAATAGCCA (14439-14456);

5. For m.652delG

CCCATAAACAAATA (639-651);

6. For m.14846G $>A$

GCGCCAAGGAGTGA (14861-14848);

7. For $m .1555 \mathrm{~A}>\mathrm{G}$

ACGCATTTATATAGAGGA (1537-1554);

8. For $\mathrm{m} .15059 \mathrm{G}>\mathrm{A}$

TTTCTGAGTAGAGAAATGAT (15080-15061);

9. For $\mathrm{m} .3256 \mathrm{C}>\mathrm{T}$

AAGAAGAGGAATTGA (3300-3286);

4. For $\mathrm{m} .12315 \mathrm{G}>\mathrm{A}$

TTTGGAGTTGCAC (12328-12316);

8. For $\mathrm{m} .13513 \mathrm{G}>\mathrm{A}$

AGGTTTCTACTCCAA (13497-13511).

The heteroplasmy level of mtDNA mutations was analyzed using a quantitative method developed on the basis of pyrosequencing technology by our laboratory ${ }^{[24-26,38,39]}$. The statistical analysis was performed using SPSS 22.0 software package ${ }^{[40]}$. The bootstrap analysis and the Spearman correlation coefficient were used. The results were considered statistically significant at $P \leq 0.05$. In addition, the results were taken into account, the significance level of which was $P \leq 0.1$. It was supposed that such results had a tendency to have statistical significance. They may be significant if the sample is expanded.

\section{RESULTS}

According to Table 1, statistically significant differences by clinical and anthropometric characteristics between samples of patients with left ventricular hypertrophy and conventionally healthy study participants were not found.

It should be noted that the age of patients with left ventricular hypertrophy ranged from 53 to 75 years. At the same time, the age of conventionally healthy participants ranged from 54 to 62 years [Table 2]. The mean age of patients with left ventricular hypertrophy was 6 years higher than the age of conventionally healthy study participants. This age difference between samples of patients with left ventricular hypertrophy 
Table 4. Spearman correlation analysis of $11 \mathrm{mtDNA}$ mutations with left ventricular hypertrophy

\begin{tabular}{|c|c|c|}
\hline Mutations & Spearman correlation coefficient & Significance \\
\hline m.652insG & -0.036 & 0.357 \\
\hline m. $5178 \mathrm{C}>\mathrm{A}$ & 0.114 & $0.038^{\mathrm{a}}$ \\
\hline m.3336T >C & -0.126 & $0.014^{a}$ \\
\hline$m .14459 G>A$ & -0.082 & $0.082^{b}$ \\
\hline m.652delG & 0.065 & 0.214 \\
\hline $\mathrm{m} .14846 \mathrm{G}>\mathrm{A}$ & -0.028 & 0.427 \\
\hline $\mathrm{m} .1555 \mathrm{~A}>\mathrm{G}$ & 0.096 & $0.064^{b}$ \\
\hline m.15059G >A & 0.064 & 0.236 \\
\hline m.3256C $>T$ & 0.057 & 0.258 \\
\hline $\mathrm{m} .12315 \mathrm{G}>\mathrm{A}$ & -0.122 & $0.017^{\mathrm{a}}$ \\
\hline $\mathrm{m} .13513 \mathrm{G}>\mathrm{A}$ & -0.034 & 0.369 \\
\hline
\end{tabular}

and conventionally healthy participants was not statistically significant. The linkage of mtDNA mutations 652insG, m.5178C >A, m.3336T >C, m.14459G >A, 652delG, m.14846G>A, m.1555A $>$ G, m.15059G $>$ A, m.3256C $>\mathrm{T}$, m.12315G $>A$ and $m .13513 \mathrm{G}>\mathrm{A}$ with atherosclerosis was described earlier by our laboratory researchers ${ }^{[24,28-31]}$. Since LVH has common risk factors with atherosclerosis, it was decided to analyze the relationship of these mutations to mtDNA with left ventricular hypertrophy.

The results of this analysis are presented in Table 4.

The direction of the linkage of mtDNA mutations with left ventricular hypertrophy was detected using the coefficient of correlation. If the Spearman correlation coefficient was positive, the investigated mutation was associated with left ventricular hypertrophy. If the Spearman correlation coefficient was negative, the mutation was associated with the absence of left ventricular hypertrophy.

According to the obtained results, mtDNA mutation m.5178C >A was significantly associated with LVH. Single nucleotide replacement m.1555A $>\mathrm{G}$ was associated with left ventricular hypertrophy at the level of significance $P \leq 0.1$. It showed a tendency to a positive correlation with $\mathrm{LVH}$. Meanwhile $\mathrm{m} .12315 \mathrm{G}>\mathrm{A}$ and m.3336T $>C$ were significantly associated with the absence of this pathology. Single nucleotide replacement m.14459G $>A$ was associated with the absence of left ventricular hypertrophy at the significance level $P \leq 0.1$. Mutation $\mathrm{m} .14459 \mathrm{G}>\mathrm{A}$ showed a tendency to negative correlation with $\mathrm{LVH}$.

\section{DISCUSSION}

Due to the fact that several mitochondria can be found in a human cell, and several copies of the mitochondrial genome can be found in the mitochondria, in particular the level of mtDNA mutations in the mitochondrial genome was analyzed. The presence of heteroplasmy threshold level of a mitochondrial genome mutation may be associated with the occurrence of the disease. Our previous article was devoted to the detection of threshold heteroplasmy level of mitochondrial genome mutations 652ins $\mathrm{G}, \mathrm{m} .5178 \mathrm{C}>\mathrm{A}$, m.3336T $>$ C, m.14459G $>$ A, 652delG, m.14846G $>A, m .1555 A>G, m .15059 \mathrm{G}>\mathrm{A}, \mathrm{m} .3256 \mathrm{C}>\mathrm{T}, \mathrm{m} .12315 \mathrm{G}>\mathrm{A}$ and m.13513G $>\mathrm{A}$, which are associated with atherosclerosis and its risk factors ${ }^{[25]}$.

Mutations m.5178C $>\mathrm{A}$ and $\mathrm{m} .1555 \mathrm{~A}>\mathrm{G}$ can be used to assess the molecular genetic predisposition of individuals to occurrence of left ventricular hypertrophy. They can also be used for family analysis of this pathology. Mutations m.12315G >A, m.3336T>C and m.14459G $>$ A could be used in the development of LVH gene therapy methods.

It is noteworthy that one of the mutations of the mitochondrial genome $(\mathrm{m} .5178 \mathrm{C}>\mathrm{A})$ can lead to a defect in the respiratory chain enzyme (NADH dehydrogenase), leading to a decrease in ATP synthesis and an energy 
deficit in the mitochondria and cells of humans. At the same time, two other mutations (m.3336T>C and m.14459G $>$ A) of this enzyme seem to have a protective, stabilizing effect and positively affect mitochondria and cardiac muscle cells. In our preliminary studies, it was found that mutation m.12315G $>\mathrm{A}$, localized in the transfer RNA-Leucine gene (recognition codon CUN), was associated with atherosclerosis ${ }^{[29]}$. However, in the present study it was found that this mutation has a protective effect on left ventricular hypertrophy. A possible reason for this may be a difference in the mechanisms of the occurrance and development of these pathologies.

It should be noted that single nucleotide substitutions which have a protective (antipathological) effect on diseases are called "protective mutations", but not polymorphisms. Since polymorphisms are neutral, they exist in populations without influencing the occurrence and development of diseases. In addition, polymorphisms do not have a protective effect in various pathologies. Therefore, the name "protective (antipathological) mutations" seems to us more correct.

It is necessary to say that in literary sources there are very few studies that have investigated the linkage of mitochondrial genome mutations with LVH. In particular, in the article of Zhu et al. ${ }^{[21]}$ the association of mutation m.4401A $>\mathrm{G}$ with left ventricular hypertrophy was found. In a research work by Govindaraj et al. ${ }^{[22]}$ heteroplasmic mutations m.4797C $>\mathrm{M}$ and $\mathrm{m} .8728 \mathrm{~T}>\mathrm{Y}$ MT-tRNA, were found to be associated with hypertrophic cardiomyopathy. In the article by Bates et al. ${ }^{[23]}$ the association of mtDNA mutation m.3243A $>\mathrm{G}$ with concentric hypertrophic remodelling and subendocardial dysfunction was studied. In none of such studies the association of the heteroplasmy level of the detected by us mtDNA mutations with left ventricular hypertrophy was analyzed.

In conclusion, five mutations of the mitochondrial genome associated with left ventricular hypertrophy were found in the present study. They can be used for molecular genetic assessment of the predisposition of individuals to the occurrence of LVH, family analysis and gene therapy of this pathology.

\section{DECLARATIONS}

\section{Authors' contributions}

Conception, design and statistical analysis: Sazonova MA

Pyrosequencing of PCR fragments: Sazonova MA, Sinyov VV

PCR: Ryzhkova AI, Khasanova ZB

DNA extraction: Sazonova MD

Administrative and material support: Sobenin IA

\section{Availability of data and materials}

The data used to support the findings of this study are available from the corresponding author upon request.

\section{Financial support and sponsorship}

This work was supported by the Russian Foundation for Basic Research (Grant \#19-015-00479)

\section{Conflicts of interest}

All authors declared that there are no conflicts of interest.

\section{Ethical approval and consent to participate}

The study was carried out in accordance with the Declaration of Helsinki. The study protocol was inspected and approved by the Ethics Committee of the National Medical Research Center of Cardiology. Each study 
participant has signed a written informed consent to participate in this investigation.

\section{Consent for publication}

Not applicable.

\section{Copyright}

(c) The Author(s) 2019.

\section{REFERENCES}

1. Lu N, Zhu JX, Yang PX, Tan XR. Models for improved diagnosis of left ventricular hypertrophy based on conventional electrocardiographic criteria. BMC Cardiovasc Disord 2017;17:217.

2. Kawai K, Sengoku H, Ishihara H, Akematsu T, Nanahoshi M, et al. Total clinical course and autopsy findings of left ventricular outflow tract obstruction due to sigmoid septum: histologically proven isolated basal septal hypertrophy. Intern Med 2017;56:2151-4.

3. Kubo T, Kitaoka H. Imaging of left ventricular hypertrophy: a practical utility for differential diagnosis and assessment of disease severity. Curr Cardiol Rep 2017;19:65.

4. Adhyapak SM, Menon PG, Rao Parachuri V. Improvements in left ventricular twist mechanics following myectomy for hypertrophic cardiomyopathy with mid-ventricular obstruction. Interact Cardiovasc Thorac Surg 2017;25:128-30.

5. Markus MR, Werner N, Schipf S, Siewert-Markus U, Bahls M, et al. Changes in body weight and composition are associated with changes in left ventricular geometry and function in the general population: SHIP (Study of Health in Pomerania). Circ Cardiovasc Imaging 2017;10:e005544.

6. Khutan H, Aggarwal S, Kajal KS, Garg R, Kaur R, et al. Study of carotid intimal medial thickness in essential hypertension with or without left ventricular hypertrophy. Ann Afr Med 2017;16:192-5.

7. Cansu GB, Yılmaz N, Yanıkoğlu A, Özdem S, Yıldırım AB, et al. Assessment of diastolic dysfunction, arterial stiffness, and carotid intima-media thickness in patients with acromegaly. Endocr Pract 2017;23:536-45.

8. Ciccone MM, Scicchitano P, Zito A, Agati L, Gesualdo M, et al. Correlation between coronary artery disease severity, left ventricular mass index and carotid intima media thickness, assessed by radio-frequency. Cardiovasc Ultrasound 2011;9:32.

9. Folsom AR, Yatsuya H, Psaty BM, Shahar E, Longstreth WT Jr. Carotid intima-media thickness, electrocardiographic left ventricular hypertrophy, and incidence of intracerebral hemorrhage. Stroke 2011;42:3075-9.

10. Pierdomenico SD, Mancini M, Cuccurullo C, Guglielmi MD, Pierdomenico AM, et al. Prediction of carotid plaques in hypertensive patients by risk factors, left ventricular hypertrophy, and epicardial adipose tissue thickness. Heart Vessels 2013;28:277-83.

11. Jobe M, Kane A, Jones JC, Pessinaba S, Nkum BC, et al. Electrocardiographic left ventricular hypertrophy among gambian diabetes mellitus patients. Ghana Med J 2015;49:19-24.

12. Rojek M, Rajzer M, Wojciechowska W, Gąsowski J, Pizoń T, et al. The relation between blood pressure components and left atrial volume in the context of left ventricular mass index. Medicine (Baltimore) 2017;96:e9459.

13. De Jong KA, Czeczor JK, Sithara S, McEwen K, Lopaschuk GD, et al. Obesity and type 2 diabetes have additive effects on left ventricular remodelling in normotensive patients-a cross sectional study. Cardiovasc Diabetol 2017;16:21.

14. Dörr M, Ittermann T, Aumann N, Obst A, Reffelmann T, et al. Subclinical hyperthyroidism is not associated with progression of cardiac mass and development of left ventricular hypertrophy in middle-aged and older subjects: results from a 5-year follow-up. Clin Endocrinol (Oxf) 2010;73:821-6.

15. Al-Daydamony MM, El-Tahlawi M. What is the effect of metabolic syndrome without hypertension on left ventricular hypertrophy? Echocardiography 2016;33:1284-9.

16. Patel SK, Wai B, Lang CC, Levin D, Palmer CNA, et al. Genetic variation in kruppel like factor 15 is associated with left ventricular hypertrophy in patients with type 2 diabetes: discovery and replication cohorts. Ebiomedicine 2017;18:171-8.

17. Sano M, Kamitsuji S, Kamatani N, Tabara Y, Kawaguchi T, et al. Genome-wide association study of absolute QRS voltage identifies common variants of TBX3 as genetic determinants of left ventricular mass in a healthy Japanese population. PLoS One 2016;11:e0155550.

18. Huber M, Lezius S, Reibis R, Treszl A, Kujawinska D, et al. A single nucleotide polymorphism near the CYP17A1 gene is associated with left ventricular mass in hypertensive patients under pharmacotherapy. Int J Mol Sci 2015;16:17456-68.

19. Xu X, Hou X, Liang Y, Li F, Pang L, et al. The gene polymorphism of LOX1 predicts the incidence of LVH in patients with essential hypertension. Cell Physiol Biochem 2014;33:88-96.

20. Boon-Peng H, Mat Jusoh JA, Marshall CR, Majid F, Danuri N, et al. Rare copy number variants identified suggest the regulating pathways in hypertension-related left ventricular hypertrophy. PLoS One 2016;11:e0148755.

21. Zhu HY, Wang SW, Liu L, Li YH, Chen R, et al. A mitochondrial mutation A4401G is involved in the pathogenesis of left ventricular hypertrophy in Chinese hypertensives. Eur J Hum Genet 2009;17:172-8.

22. Govindaraj P, Khan NA, Rani B, Rani DS, Selvaraj P, et al. Mitochondrial DNA variations associated with hypertrophic cardiomyopathy. Mitochondrion 2014;16:65-72.

23. Bates MG, Hollingsworth KG, Newman JH, Jakovljevic DG, Blamire AM, et al. Concentric hypertrophic remodelling and 
subendocardial dysfunction in mitochondrial DNA point mutation carriers. Eur Heart J Cardiovasc Imaging 2013;14:650-8.

24. Sazonova M, Budnikov E, Khasanova Z, Sobenin I, Postnov A, et al. Studies of the human aortic intima by a direct quantitative assay of mutant alleles in the mitochondrial genome. Atherosclerosis 2009;204:184-90.

25. Sazonova MA, Ryzhkova AI, Sinyov VV, Galitsyna EV, Orekhova VA, et al. New markers of atherosclerosis: a threshold level of heteroplasmy in mtDNA mutations. Vessel Plus 2017;1:182-91.

26. Sazonova MA, Postnov AIu, Orekhov AN, Sobenin IA. A new method of quantitative estimation of mutant allele in mitochondrial genome. Patol Fiziol Eksp Ter 2011;4:81-4.

27. Sobenin IA, Mitrofanov KY, Zhelankin AV, Sazonova MA, Postnov AY, et al. Quantitative assessment of heteroplasmy of mitochondrial genome: perspectives in diagnostics and methodological pitfalls. Biomed Res Int 2014;2014:292017.

28. Sazonova MA Association of mitochondrial genome mutations with lipofibrous plaques in human aortic intima. Patol Fiziol Eksp Ter 2015;59:17-28.

29. Sazonova MA, Sinyov VV, Ryzhkova AI, Galitsyna EV, Khasanova ZB, et al. Role of mitochondrial genome mutations in pathogenesis of carotid atherosclerosis. Oxidative Medicine and Cellular Longevity 2017;2017:1-7.

30. Sazonova MA, Sinyov VV, Barinova VA, Ryzhkova AI, Zhelankin AV, et al. Mosaicism of mitochondrial genetic variation in atherosclerotic lesions of the human aorta. Biomed Res Int 2015;2015:825468.

31. Ryzhkova A, Sazonova M, Sinyov V, Galitsyna E, Barinova V, et al. Detection of threshold heteroplasmy level of mtDNA in lypofibrous plaques of human aortic intima. Atherosclerosis 2016;252:e80.

32. Sazonova, MA, Amosenko, FA, Kapranov NI, Kalinin VN. Molecular genetic analysis of TUB18 and TUB20 intragenic polymorphism and various mutations of the CFTR gene in the Moscow region. Genetika 1997;33:1303-7. (in Russian)

33. Amosenko FA, Sazonova MA, Kapranov NI, Trubnikova IS, Kalinin VN. Analysis of various polymorphic markers of the CFTR gene in cystic fibrosis patients and healthy donors from the Moscow region. Russ J Genet 1995;31:457-9.

34. Amosenko FA, Trubnikova IS, Zakhar'ev VM, Bannikov VM, Sazonova, MA, et al. TUB9 polymorphism in the CFTR gene of cystic fibrosis patients, carriers, and healthy donors from the Moscow region. SSCP and restriction analyses. Genetika 1997;33:257-61. (in Russian)

35. Alderborn A, Kristofferson A, Hammerling U. Determination of single-nucleotide polymorphisms by real-time pyrophosphate DNA sequencing. Genome Res 2000;10:1249-58.

36. Simou M, Kouskouni E, Vitoratos N, Economou E, Creatsas G. Polymorphisms of platelet glycoprotein receptors and cell adhesion molecules in fetuses with fetal growth restriction and their mothers as detected with pyrosequencing. In Vivo 2017;31:243-9.

37. Pu D, Pan R, Liu W, Xiao P. Quantitative analysis of single-nucleotide polymorphisms by pyrosequencing with di-base addition. Electrophoresis 2017;38:876-85.

38. Sazonova MA, Budnikov YY, Khazanova ZB, Postnov AY, Sobenin IA, et al. Direct quantitative assessment of mutant allele in mitochondrial genome in atherosclerotic lesion of human aorta. Atherosclerosis Suppl 2007;8:45-6.

39. Sazonova M, Andrianova I, Khasanova Z, Sobenin I, Postnov A. Quantitative mitochondrial genome mutation investigation and possible role of the somatic mutations in development of atherosclerotic lesion of human aorta. Atherosclerosis Suppl 2008;9:113.

40. IBM SPSS software. Available from: https://www.ibm.com/analytics/us/en/technology/spss. [Last accessed on 21 Feb 2019] 